\title{
Artelogie
}

Recherche sur les arts, le patrimoine et la littérature de l'Amérique latine

$4 \mid 2013$

Fêtes et célébrations en Amérique latine

\section{Entre el repique y el estruendo, la celebración del 5 de Mayo en Puebla, 1868-1930}

Rosalina Estrada Urroz y Enrique Cano Galindo

\section{OpenEdition}

\section{Journals}

Edición electrónica

URL: https://journals.openedition.org/artelogie/6607

DOI: 10.4000/artelogie.6607

ISSN: 2115-6395

\section{Editor}

Association ESCAL

\section{Referencia electrónica}

Rosalina Estrada Urroz y Enrique Cano Galindo, «Entre el repique y el estruendo, la celebración del 5 de Mayo en Puebla, 1868-1930», Artelogie [En línea], 4 | 2013, Publicado el 02 febrero 2013, consultado el 01 diciembre 2021. URL: http://journals.openedition.org/artelogie/6607 ; DOI: https://doi.org/ 10.4000/artelogie.6607

Este documento fue generado automáticamente el 1 diciembre 2021.

Association ESCAL 


\title{
Entre el repique y el estruendo, la celebración del 5 de Mayo en Puebla, 1868-1930
}

\author{
Rosalina Estrada Urroz y Enrique Cano Galindo
}

\section{Introducción}

1 La conmemoración es un lugar de construcción y deconstrucción de símbolos, de acuerdo a las circunstancias adquiere un carácter específico, fluctúa de un lado a otro, se repite, se recompone, se deslava y dota de nuevos contenidos. Los próceres recorren, igual que en los avatares bélicos, las vicisitudes del camino de la política, un camino sinuoso, que se empieza a construir desde el momento mismo del hecho, ahí nace el mito y el imaginario con su poder creador se desarrolla a sus anchas, poniendo en cada acto de conmemoración un ingrediente más de significados múltiples. En la fiesta se recuerda el pasado, un pasado pleno en el que ya se empiezan a construir los símbolos de la patria.

Puebla enfrenta el siglo XIX con una conflictiva situación. Liberales y conservadores se oponen y la expresión de estas diferencias toma cuerpo en la intervención francesa, donde el conservadurismo se hace presente a través de la recepción de las fuerzas invasoras. La alianza tripartida constituida en 1861 por los gobiernos de Francia, Inglaterra y España no tiene vida duradera, ante los agravios antes compartidos, el gobierno francés protagoniza la intervención en solitario con el fin de instaurar en el poder al archiduque Maximiliano de Habsburgo. La ciudad de Puebla es una de las primeras a detener la marcha de las tropas francesas, la batalla del 5 de Mayo de 1862 encabezada por el general Ignacio Zaragoza derrota a las fuerzas invasoras. El triunfo no sería definitivo, un año después Puebla de Zaragoza vive uno de los sitios más cruentos de su historia.

3 Es el efímero momento el que queda en la memoria, ahí se agiganta la esfinge de Zaragoza, alimentada por el orgullo del triunfo, pero también por su muerte temprana 
acaecida cuatro meses después del acontecimiento. Las cualidades del líder son símbolo de gallardía y de honorabilidad, atributos resaltados desde sus propias palabras: Estoy muy contento con el comportamiento de mis Generales y soldados. _Todos se han portado bien._ Los franceses han llevado una lección muy severa; pero en obsequio de la verdad diré: que se han batido como bravos, muriendo una gran parte de ellos en los fosos de las trincheras de Guadalupe. ${ }^{1}$ El coronel Echenique se hace la siguiente pregunta, la cual va a repetirse en todos los textos que se refieren a esta gesta: ¿En qué nación, en qué idioma, en qué circunstancia se ha escrito un parte más modesto, más verídico, más elocuente y más patriótico?²

4 A la luz de los planteamientos Clausewitz, Glucksman descubre en la guerra el lugar decisivo que ocupa la batalla por encima de la multiplicidad caótica del conflicto global. La batalla es concluyente en el acto por su fuerza material pero también por su grandeza moral, es ahí donde manifiesta la última verdad. ${ }^{3}$ En el 5 de Mayo la grandeza moral es repetida, las cualidades de los líderes se exaltan, los traidores son rechazados o ridiculizados. A través de ella se representan ilusiones y anhelos, sentimientos y emociones. En la memoria se encuentra el ya glorioso 5 de Mayo, el cual atraviesa el presente-futuro, el futuro cercano le otorga, a pesar de su brevedad, la solemnidad de las rupturas inaugurales. ${ }^{4}$

5 Es la Puebla la que ostenta con orgullo el emblema de la soberanía, el 5 de Mayo se reitera en palabras, fuegos, luces y sonidos. Los próceres se pasean por las calles para de nuevo mostrar valores de dignidad y valentía, para confirmar el triunfo momentáneo, que anuncia la derrota total del Imperio. La fiesta adquiere un esplendor inusitado, se refrenda el ceremonial, hasta volverse monótono y formal, en la calle no se sabe qué se resalta, el amor a la patria, el 5 de Mayo o la Independencia.

\section{La conmemoración y su larga vida}

6 Terminada la intervención y restaurada la República, Puebla inicia la lenta recuperación material luego de los estragos provocados por la guerra y del sitio sufrido en 1863, aunque las celebraciones por la independencia no se interrumpen, seis años después de la batalla de Loreto y Guadalupe, la Junta Patriótica de Puebla organiza mediante bando solemne ${ }^{5}$, el acto de conmemoración que marca la fundación de la tradición cívica más importante para la ciudad de Zaragoza.

7 Entre 1868 y $1877^{6}$ la mencionada Junta es la entidad encargada de organizar las "solemnidades", en ellas no solo se busca mantener en la memoria el hecho de armas, también se excita el patriotismo de los poblanos a través de la decoración e iluminación de las calles, fachadas de casas, negocios y edificios públicos Desde el inicio se involucra a la población para que participe de forma espontánea con su presencia en la calle, en la plaza y en la "procesión cívica". En el paseo cívico, se le pone al lado de la autoridad en actos como el repique de campanas, las salvas, los vítores, transitando por el discurso, el desfile y la serenata.

8 Los íconos de la patria se enriquecen con personajes vivos o estampas, en 1868 el Ayuntamiento solicita a la Junta Patriótica los retratos de los Beneméritos héroes Hidalgo y Zaragoza y la bandera nacional. Las celebraciones fueron acompañadas desde el primer momento con el busto o retrato de Ignacio Zaragoza, junto a esta figura, como héroe de la paz y defensor de la República, aparece Porfirio Díaz, quien se convirtió en un elemento singular de la fiesta cívica: se trataba del héroe viviente. ${ }^{7}$ 
9 Entre 1881 y 1913 la conmemoración se institucionaliza; el acto cuenta con un programa preparado y publicado de antemano y con un presupuesto determinado, acordado previamente por el Ayuntamiento a través del Patronato de fiestas, aprobado por el Jefe Político, quien es pieza clave en la administración de la dictadura. En sus detalles es similar en todos estos años, en ella se combina lo festivo, lo cívico y lo político con un ritmo y un tiempo perfectamente definidos que no se interrumpe ni con la caída del dictador o el derrocamiento de Francisco I. Madero.

Durante el porfiriato el 5 de Mayo se convirtió en una oportunidad para mostrar las bondades de la paz y el progreso. Las comitivas del "paseo cívico" que recorren invariablemente las dos rutas entre el palacio de gobierno al Paseo Hidalgo o al Paseo Bravo se nutren con nuevos elementos sociales. En la fiesta se resaltan valores como el patriotismo, la cultura, la civilización y la capacidad de memoria de los poblanos al congregarse alrededor del invicto general Ignacio Zaragoza. La fecha sirve también para inaugurar obras públicas de servicio y ornato. Este periodo marcó el modelo de celebración para las décadas posteriores.

11 En los momentos más críticos de la Revolución Mexicana tanto en lo político como en lo social la cita histórica no se suspende. Precisamente la efeméride tuvo la función de reforzar la idea de libertad e independencia, pero ajustada a los nuevos tiempos. De este modo, entre 1914 y 1930, cada presidente municipal, por medio de la Comisión de festividades o la de Gobernación, es encargado de organizar el festejo respectivo de acuerdo a los ideales de la Revolución triunfante. Sobre la base de fechas pasadas el rito patrio se repite en los aspectos y personajes de costumbre, aunque nuevos elementos aparecen y se superponen a la vieja rutina cívica: tal parece que la memoria ya no es tan fresca y lo espontáneo comienza a desaparecer, la ceremonia toma distancia de los hechos.

12 En la celebración no faltan las palabras, a través de los discursos se realiza el recorrido histórico, se pondera el origen de los mexicanos, su pasado indígena, la valentía de los combatientes y el poderío y orgullo de las tropas francesas que viven un fracaso inesperado. La derrota de 1862 es narrada y caracterizada a través de múltiples metáforas: ...aquellos soldados aguerridos, que por el humo de cien batallas tenían la frente oscurecida, aquellos que reflejaban en su mirada el encono del enemigo... que llevaban sobre el robusto pecho las cruces recientes de Crimea, volvieron la espalda a la cinta de fuego que coronaba las almenas de ese monumental Guadalupe... ${ }^{8}$ Francisco G. Luque resalta en 1909, la soberanía nacional, insistiendo en la obra de la civilización y la liberación de la cadena extranjera, sin embargo realiza una advertencia premonitoria: Más no por esto podemos afirmar que hemos segado toda tiranía: nos queda la intrapatria. Si señores: examinad atentamente el espíritu individual de los mexicanos en nuestro medio social y tendréis ante vosotros esta triste verdad: estamos plagados de tiranos. ${ }^{9}$ En estas palabras parecería anunciarse ya un nuevo tiempo.

\section{La fiesta y su estruendo}

13 A las dos de la mañana del 5 de Mayo de 1868, la población de la ciudad recorría las calles vitoreando a los héroes; varias músicas se tocaban, bulliciosas piezas, y por todas partes se improvisaban bailes: los himnos patrióticos y los cantos nacionales se elevaban por los aires saludando a la aurora de tan bello día. Se realiza la primera conmemoración, la batalla habita fresca en la memoria, el repique al vuelo y las salvas 
de artillería lo reiteran, las glorias de 1862 causan fiesta. La gesta militar está presente, se teatraliza el 5 de Mayo, a las tres de la tarde se dan los mismo toques de alarma, ante la aproximación de los franceses. La ceremonia abarca todo el día, a las diez y cuarto de la mañana, un cañonazo en la Plazuela de Analco, después los toques de rebato en la catedral, y a las dos y media bandas militares en la plaza de la constitución, los tonos marciales permanecen todo el día.

Los símbolos de la batalla se hacen presentes través de los, calificados de magníficos, fuegos artificiales, se queman a las 9 de la noche y ponen fin a la celebración. El aire festivo se representa a través de varias coronas y rosas de colores hermosísimos y cohetes de luz, la batalla toma cuerpo en la pieza que ilumina el cerro y el templo de Guadalupe coronada por el pabellón nacional. ${ }^{10} \mathrm{En}$ el desfile se vitorea a los héroes del 5 de Mayo, himnos patrióticos y cantos nacionales son entonados. Los edificios públicos son iluminados.

El desfile igual que otras actividades se institucionaliza, en 1870, la Junta Patriótica de la capital y el Gobierno, aprueban el programa para conmemorar el 5 de Mayo de 1862, después de la salvas de artillería y el repique general, es izado del pabellón nacional en los edificios públicos y las bandas y músicas militares recorren las calles de la ciudad. A las nueve de la mañana se reúne en el palacio la comitiva, el ciudadano Ignacio Romero Vargas, Gobernador Constitucional del Estado Libre y Soberano de Puebla se traslada acompañado al Paseo Viejo, donde se pronuncian discursos encomiásticos por los oradores oficiales. El gobernador y la Junta Patriótica realizan la distribución pecuniaria destinada a los mutilados de guerra, viudas y huérfanos de la guerra contra las fuerzas invasoras. A las tres de la tarde, después de las campanadas de rebato, se repiten demostraciones en memoria de la hora en que finaliza la función de armas del día 5 de Mayo de 1862, a las seis se arría el pabellón nacional, dando fin el memorable día. La fiesta continúa, a las cuatro de la tarde la música se escucha en el Paseo Viejo y el Paseo Nuevo, la diversión pública se prolonga, de siete a once de la noche lucen las iluminaciones y en el zócalo de la plaza principal se sitúa la banda militar para la serenata con la que se obsequia al pueblo, mientras, tienen lugar los fuegos de artificio. 11

En los años del Porfiriato la ceremonia adquiere esplendor, el programa de 1888 es uno de los más elaborados. El jefe político de Puebla, Joaquín Pita, lo da a conocer: A las 6.00 horas se iza el Pabellón nacional en los edificios públicos, con los honores de ordenanza, saludando con repiques a vuelo y salvas de cohetes. Las bandas militares recorren las principales calles de la ciudad y tocan diana, a las 8.30 horas en el Palacio de Gobierno se reúne el personal que acompaña al gobernador a la ceremonia oficial. La comitiva es amplia, incluye vecinos de los barrios, personal del ayuntamiento, gremios, representantes de la cámara de comercio, funcionarios y empleados federales, sociedades varias, cónsules y representantes de las colonias extranjeras, así como los miembros del poder judicial. A la llegada del gobernador, las bandas ejecutan el Himno Nacional. El secretario del Ayuntamiento da lectura al parte oficial del la batalla del 5 de Mayo de 1862. El acto comprende también el discurso del Profesor Nicandro Fernández; obertura por la banda del Batallón Zaragoza y las condecoraciones por parte del general en jefe de la Zona en base al acuerdo relativo de la Secretaría de Guerra.

A las 11:00 horas, el gobernador y las personas invitadas se dirigen en automovil al lugar de la batalla, en el fuerte de Guadalupe depositan coronas en honor de los héroes muertos. Posteriormente el gobernador inaugura las casas de bombas, construidas para 
el saneamiento y abastecimiento de agua potable situadas en el Paseo Hidalgo y en la Cieneguilla. A las 15 horas se realizan repiques a vuelo en todos los templos y nutridas salvas de cohetes, indicando de nuevo la hora en que las armas nacionales obtienen el triunfo. Las bandas militares establecidas en la Plaza de la Constitución marchan para sus cuarteles al toque de diana.

Durante todo el día se realizan verbenas populares en el Paseo de Hidalgo y en la Plazuela de Antuñano hay cucañas y juegos acrobáticos por la tarde. Los comerciantes que establecen puestos en esos lugares, con excepción hecha de las de bebidas embriagantes, no pagan impuestos. Las bandas del $12^{\circ}$ Regimiento y la Municipal dan audiciones en los dos paseos, desde las 16:00 hasta las 18:00 horas. A las 19:30 horas, desde el Palacio Municipal, sale una procesión de antorchas acompañada de la Banda Municipal.

Realizar el recorrido por la fiesta del 5 de Mayo no es una cuestión sencilla, las diferencias entre una u otra celebración son tenues, quizá lo único que las distinga sea su intensidad, los héroes celebrados y la institucionalización creciente de las ceremonias. En este largo recorrido que va de 1868 a 1930, en un formato similar, no falta el arriado del pabellón nacional y la conmemoración es acompañada de una ceremonia donde se repiten la música, los repiques, cañonazos, salvas, dianas, fuegos artificiales, bandas militares, los diversos espectáculos, el decorado citadino y el desfile. Merece especial atención la participación de las bandas militares, los espacios privilegiados donde se presentan son el Paseo Hidalgo, la Plaza principal y el Paseo Bravo, algunas veces se trasladan itinerantes por la ciudad. Las bandas constituidas por el $7^{\circ}$ Batallón, el Batallón Zaragoza y la Banda Municipal tienen la encomienda de amenizar la fiesta. Los programas reflejan desde finales del siglo XIX, una disminución de actividades militares para dar cabida a otro tipo de diversiones.

21 El Paseo Bravo es el lugar en donde se desarrolla una inmensa actividad recreativa, sobresalen las funciones de acróbatas, a partir de 1872 y hasta 1911, es uno de los espectáculos que no puede faltar, el pueblo se derrama por todos los ambientes donde hay diversión. En 1872 se acumulan los espectáculos, función de acróbatas en el paseo Bravo; japoneses en la plaza de toros con la presentación de acróbatas y funámbulos (equilibristas); zarzuelistas en el Teatro Principal y músicas militares en los Paseos de Hidalgo y San Javier. La fiesta musical se prolonga hasta la hora del crepúsculo, momento de arriar las banderas. En 1899, a propuesta de la Comisión de celebraciones del 5 de Mayo, la función de acróbatas es sustituida por Una ascensión en globo libre, la cual se verifica entre tres y cuatro de la tarde en la Plazuela de San José por el aeronauta Mr. Baldwin. ${ }^{12}$

La fiesta culmina con los fuegos artificiales, momento esperado pleno de luz y colores, desde 1868 es un elemento presente, existe una industria que los pone a disposición de las diferentes celebraciones, así se reproducen los símbolos de la patria libertaria. Las piezas presentadas, son conmemorativos pero muestran también el sentido lúdico del arte pirotécnico. Es una solemnidad que confirma la victoria sobre las tropas francesas, el lugar predilecto es la plaza principal y las cuatro esquinas de la catedral, los lugares se amplían, de la plaza principal se trasladan en 1893 a la Plaza de San José, en 1894 a la carrera formada por las calles de Mercaderes, Santa Clara y Santa Teresa, en 1895 en la avenida formada por las calles de Zaragoza y Guadalupe, en 1910 en la Plazuela de Antuñano, aunque la Catedral y la Plaza de la Constitución siguen siendo lugares privilegiados. 
El señor Mariano Castillo es uno de los principales proveedores, en 1930 ofrece al ayuntamiento una serie de figuras, las cuales reiteran la importancia de la batalla de Puebla y el afán por hacerla permanecer en la memoria, aunque no faltan figuras absolutamente alejadas de la conmemoración. Para iniciar los fuegos propone un aparato combinado con una campana eléctrica que muestra el nombre de la pieza que se va exhibir. La batalla es representada por un castillo principal dividido en tres tiempos, inicia con un simulacro con truenos de fusilería y de cañón lo que aparentará la batalla 5 de Mayo, de aquella fecha memorable, en segundo lugar un nuevo tiroteo con luces de colores, en un tercer tiempo surge el cerro de Guadalupe con sus torres y el sonido de las campanas, finaliza con una hermosa aureola de chispas de oro. Propone también un hermoso arco triunfal, sostenido por cuatro columnas, en el centro el medio busto del señor General Miguel Negrete ${ }^{13}$ descansado sobre un pedestal y alrededor un laurel de hermosas luces verdes, en la parte superior una bandera tricolor, a la derecha e izquierda dos soldados y dos palmeras que sirven de acompañamiento y al terminar todos estos aparatos se formará una hermosa aureola de chispas de fuegos brillantes. Además de un rótulo que diría: Ayuntamiento de 1930, con luces, banderas tricolores, verde, blanco y colorado con ráfaga de oro. ${ }^{14}$

La fiesta rebasa en su desarrollo el sentido patriótico, a lo largo de los años se constituye en un esparcimiento más, a pesar que continúan constantes las representaciones de la batalla, la diversión se adereza con otros elementos que le son extraños. En el ofrecimiento para conmemorar esta gesta, se ponen a la disposición del ayuntamiento varias figuras que no tienen una relación directa con la conmemoración, así el mencionado proveedor ofrece: el proal chino pieza giratoria completamente nueva, de hermosos colores rojos verdes y azul con lluvia perla combinada con hermoso fuego chino y rasgos brillantes; la fuente maravillosa pieza giratoria automática que se abre y se cierra en cuyo centro se destaca el cuerpo escultural de una bella mujer cargando sobre su cabeza un jarrón romano y a sus pies cuatro hermosos cisnes que echan agua por la boca a cambio de colores; el hombre que baila Charleston; el tecolote que mueve sus alas y en tres variaciones distingas, el cubilete mexicano y el enano y el gigante, movidos por cohetes obscuros en los que resaltan hermosos relámpagos a colores. $^{15}$

También existen en el mercado proveedores que proponen diversos artículos de carácter patriótico. La fábrica de banderas del señor Gabriel Echaniz ofrece, faroles, cortinas y estandartes para balcones, retratos y festón de papel fino. ${ }^{16} \mathrm{La}$ conmemoración tiene sus espacios y sus imágenes, el fuerte de Guadalupe es el lugar sacralizado, ahí se rinde tributo a los héroes y se reiteran los valores, la memoria se esculpe ahora en piedra para que no se olvide y se recuerde también que cada gobierno tiene su preocupación por no olvidar.

\section{Estatuas, bustos y monumentos en su deambular por la ciudad}

Como lo señala Maurice Aghulon, en el siglo XIX, la escultura se convierte en una forma de expresión de la política ${ }^{17}$, en este caso de la batalla y su personaje principal esculpido en la memoria, reciente y pretérita, no es solamente un objeto de propaganda, sino la reiteración y apropiación del pasado y objeto de decoración urbana. El Club "Sufragio Popular" en sesión extraordinaria del 12 de Mayo de 1888, aprueba: Honrar de una 
manera digna la memoria de aquellos que en defensa de la patria sucumbieron por mantener incólumes sus derechos y sus libertades... Caudillo de aquella heroica jornada, digna de eterna remembranza, fue el invicto general Ignacio Zaragoza, y justo es, que de una manera que perpetúe su memoria, se recuerde ese hecho en que México supo colocarse a la altura de los pueblos verdaderamente libres. ${ }^{18}$

El mencionado club considera un deber de elevado patriotismo preservar la memoria para que recuerdos tan grandiosos, no se hundan en la noche del olvido, por ello propone erigir en el Paseo Hidalgo de la ciudad de Puebla o en el lugar que designe el Ayuntamiento una estatua conmemorativa en honor del invicto general Zaragoza. El acto de colocación de la primera piedra es apadrinada por los poderes del estado y tiene lugar el día 31 de julio de 1888, aniversario del natalicio del héroe del 5 de Mayo. Con el objetivo de cumplir con este cometido se solicita cooperación de las autoridades federales, de los estados, de los miembros del ejército y de los particulares. La redacción del Periódico El Pensamiento Libre es gestora del proyecto, además se requiere sanción legal al Superior Gobierno del Estado y se pide al ayuntamiento la designación del lugar en que deba colocarse la primera piedra y la cooperación de su Honorable Legislatura para la realización de esa idea. Este mismo día el presidente Porfirio Díaz coloca otra piedra, la del monumento que la Colonia Francesa erige en memoria de los mexicanos y franceses perecidos en la batalla del 5 de Mayo, se manifiesta así la concordia entre viejos enemigos. ${ }^{19}$

De acuerdo al gobierno en turno y a los planes de conmemoración, los espacios de culto hacia los héroes de esta gesta deambulan por la ciudad hasta instalarse en un lugar de memoria, lo suficientemente empedrado para que no ofrezca duda: los fuertes. La estatua de Zaragoza circula por la ciudad, se ubica inicialmente en la Plazuela de las Piadosas, el 22 de noviembre de 1896 es trasladada al Paseo Hidalgo (hoy 22 oriente y 10 norte) y en 1944 es removida de este lugar para ubicarse en la calzada que sube hacia los fuertes, en 1976 en la conmemoración de la batalla se inaugura el actual monumento. ${ }^{20}$

La población con su presencia contribuye a la consagración de los espacios, pero también merecen de su parte calificativos y críticas. En 1930, el comerciante Emilio Contreras ofrece al Presidente Municipal Antonio Arellano un par de anteojos, pues al dirigirse al cerro de Loreto observa que el General Zaragoza no los posee. ${ }^{21} \mathrm{El}$ Monumento al centenario de la batalla de Puebla, instalado al final de la calzada Ignacio Zaragoza y la autopista México Orizaba en 1962, ha sido popularmente llamado "El Taco".

30 El año de 1962, centenario de la batalla, se realiza el Monumento a la Victoria el cual será colocado en la zona monumental de los Fuertes de Loreto y Guadalupe. La Sección del Sindicato de Maestros del Sistema Estatal, tiene una importante junta para tratar la iniciativa municipal de la construcción de dicho monumento, con el objetivo de que sus secciones aprueben la colaboración y participen con el gobierno en tal actividad. ${ }^{22} \mathrm{En}$ julio de 1961 en la junta de cabildo que celebra el presidente municipal Eduardo Cué Merlo es aprobado el Gigantesco monumento a los héroes de la batalle del 5 de Mayo, cuyo costo asciende a $\$ 1,200,000.00$. Como un homenaje de la ciudadanía poblana al centenario de la epopeya, el enorme monumento se realiza en la ciudad de México y se le otorga el nombre: Victoria del 5 de Mayo. ${ }^{23}$

31 En el mes de septiembre de 1961, a 80 metros al norte de la estatua ecuestre del General Zaragoza, es colocada la primera piedra del monumento a la Victoria. En el acto se da 
lectura al pergamino, el cual es introducido en cilindro de cobre por el presidente municipal acompañado de varias monedas del año, además de bonos de cooperación, para después ser colocado en el nicho formado en la primera piedra..$^{24}$ Los diferentes elementos relativos a la conmemoración no se limitan a los monumentos, varios sitios albergan otro tipo de expresiones, entre ellas placas que muestran momentos de la batalla y la intervención.

\section{Puebla, 5 de Mayo de 1962 Zaragoza representado en el presidente Adolfo López Mateos}

La celebración del 5 de Mayo resulta un acto que se reinventa, se acondiciona, tiene cambios y permanencias. Desde un principio tiene la intención de cohesionar a la población alrededor de los gobiernos en turno, con un doble carácter: patriótico y festivo. Las iniciativas provienen de las diferentes instancias gubernamentales: la corporación municipal, el Concejo Municipal o el Patriótico Ayuntamiento, las cuales se encargan de la organización de la festividad en la que los habitantes de la ciudad son actores e invitados principales. La ciudad vive su fiesta, se adorna e ilumina, pone en juego sus recursos y construye imágenes, frases y conceptos que la distinguen de otras celebraciones cívicas en diferentes puntos del país. A cien años, en un presente que quiere reinventarse aparece la ambigüedad del sitio y la nueva apropiación que quiere hacerse de él, pues se reitera en tres sentidos: material, simbólico y funcional. ${ }^{25}$

Hemos llegado a los cien años, la conmemoración está por definirse, desde 1960 se inician los preparativos, las instituciones son las tradicionales. En agosto de 1960 se instalan las oficinas del concejo organizador de la feria y de los festejos conmemorativos del 5 de Mayo de 1862, en ella se atenderán y se prepararán los programas respectivos. ${ }^{26}$ Entre los planes más importantes: la restauración de los fuertes, el desarrollo de la infraestructura y la inauguración de obras de gran magnitud como la autopista México-Puebla.

Con la participación del gobierno del Estado, el INAH y el Instituto Poblano de Antropología e Historia la zona histórica recibe especial atención. ${ }^{27}$ La restauración de los fuertes Loreto y Guadalupe se inicia en diciembre de 1861 y debería tomar tres meses. Una de las primeras preocupaciones es el respeto a la su fisonomía original, para el de Loreto se planea una gran transformación, pues contaría con maquetas, juegos de luces, sonido, murales, salón de banderas, pinturas, dibujos, armas y objetos históricos relacionados con la batalla. El fuerte de Guadalupe sería hermoseado y reconstruido en su forma original y se convertirá en atractivo arqueológico, además se pretende equiparlo con piezas de artillería. Se planea también la construcción del auditorio, el museo regional y la escuela de artesanía, en ello intervendría La Secretaría del Patrimonio con un presupuesto con 37 millones de pesos. ${ }^{28} \mathrm{El}$ auditorio constituirá un alarde de ingeniería moderna: su aspecto contempla una gran cúpula de 17 metros de altura por 60 de diámetro y la instalación de 2,000 butacas, vestíbulo e instalaciones de servicio. ${ }^{29}$

La restauración parece ir más allá de la conservación, el pasado hace ruido en el presente, El Sol de Puebla destaca: Destruyen el valor histórico de los fuertes. Reconstruir es para la piqueta oficial destruir lo poco que queda. Como van las obras tal parece que se perderá la huella del tiempo en las ruinas. El subsecretario de bienes inmuebles y urbanismo, al ser 
entrevistado sostiene que debido a que el fuerte de Loreto tiene acabados de diferentes fechas, es necesario darle el aspecto que poseía en 1862, agrega que la forma inicial de la capilla será respetada íntegramente. ${ }^{30}$

La Secretaría de Defensa Nacional otorga a la autoridad militar el poder de vigilar los trabajos, el objetivo es que no se realicen destrucciones y se preserve el valor histórico. ${ }^{31}$ El Sol de Puebla se pregunta ¿Para qué sirven los institutos de Historia?", resulta indispensable la acción del INAH e IPAH que son los que saben -o debieran saber tales cosas- $y$ los que tienen -o deberán tener- el máximo derecho para hablar y orientar a la oponión pública para guiar a quienes compete la ejecución de los trabajos. El silencio que han guardado estos institutos y más aún el que se obstinan en mantener sobre asuntos de tanta importancia nacional, pueden conducir a que se piense que pese a sus logros e impresionantes títulos no sean de mayor utilidad ni cuando su intervención y sus palabras resultan necesarias y hasta indispensables. ${ }^{32}$ Los diferentes organismos que intervienen en la restauración realizan visitas y dan declaraciones para insistir que los trabajos se hacen con respeto del valor histórico.

La conmemoración se mueve entre la preservación y el espectáculo. Se trasladan a Puebla valiosas reliquias de la batalla, entre ellas una casaca del general Zaragoza y una bandera del primer batallón activo de Puebla. Los objetos son entregados al secretario de la Defensa por quien los conservaba: la familia Campuzano Fernández. Seis auténticos cañones de la batalla son trasladados a la ciudad y pretenden ser instalados en la zona de los fuertes. ${ }^{33} \mathrm{~A}$ la vez se planean espectáculos de atracción mundial entre los que sobresale el teatro, la música y los desportes.

La feria adquiere un lugar fundamental, para su realización, se proyecta levantar magníficas y modernas construcciones, dotadas de oficinas de información, socorro médico, alojamiento, pabellones y teatro. Se tendría acceso al recinto a través de la autopista México-Puebla, cuya inauguración se realizaría el 5 de Mayo. Sería un evento con repercusión internacional, inusitado en Puebla, en el cual diferentes paises invitados expondrían lo mejor de su producción agrícola, industrial y ganadera. Cada estado de la república tendría un pabellón, en el cual se llevarían adelante danzas de todo el país, concursos de carteles y timbres postales, además de venta de productos típicos de Puebla. El licenciado Nicolás Vázquez sostiene que: todos los aspectos de la feria han sido perfectamente planeados y previstos hasta en sus menores detalles ${ }^{34}$

El programa de cien años de la batalla, tiene por lo general las mismas características de aquellos reseñados. En el centenario de acuerdo a solicitud realizada por el gobierno del estado a través de su secretario Lic. Alfonso Vélez López, es aprobado por el presidente de la república, ${ }^{35} \mathrm{En}$ él se repiten los elementos tradicionales, entre los cuales destaca la iluminación de los fuertes, a través de la instalación de lámparas de diseño moderno en las avenidas que llevan a él, así como rotondas y zonas verdes, además de "spots" de luz directa o reflectores para iluminar los edificios de valor histórico, así como unidades ornamentales. El objetivo es alumbrar interiores y exteriores, pues las salas de los museos acondicionadas en Loreto y Guadalupe estarán abiertas hasta el anochecer. Será la comisión respectiva la que decida las adaptaciones que deberán hacerse a este proyecto. ${ }^{36}$ Además de aquellos de los fuertes, se toma también la iniciativa de reestructurar los museos de la ciudad, entre ellos el del Alfeñique, Bello, Santa Mónica y el de la Revolución. El objetivo es transformar estos espacios, el de los fuertes de Loreto y Guadalupe debería convertirse en Museo de la Guerra y el de Santa Mónica en arte religioso. Además de esta división, se hace 
necesaria una literatura explicativa apegada a la realidad y aprobada por autoridades a fin de evitar las interpretaciones vulgares que en lugar de causar admiración causan hilaridad en personas cultas. ${ }^{37}$

Para la conmemoración se prepara el desfile militar, el simulacro de la batalla, el develamiento de monumentos y la instalación de placas conmemorativas. Además se iniciará un período de eventos culturales, científicos y deportivos, con el objetivo de fomentar el turismo nacional e internacional..$^{38} \mathrm{El} \mathrm{Sol} \mathrm{de} \mathrm{Puebla} \mathrm{destaca} \mathrm{la} \mathrm{tardanza} \mathrm{con}$ que se realizan los preparativos y los peligros de que la celebración no se realice, pues es confuso el papel de las organizaciones y del financimiento, pues al parecer el gobierno federal no aportará ni un centavo. ${ }^{39}$

41 Surge la propuesta de que los restos mortales del general Ignacio Zaragoza sean trasladados a Puebla, la idea parece tener eco entre los poblanos de nacimiento, sobre todo porque sus restos permanecen en el panteón de San Fernando, que se situado en pleno centro de la capital, ha sido cerrado. Por otro lado se afirma que el pequeño monumento que tiene en su tumba no recibe el cuidado que merece. ${ }^{40}$

42 La celebración del centenario ha llegado. Desde el día 4 de mayo de 1962 El Sol de Puebla destaca en sus titulares: Puebla se convertirá mañana en altar para honrar a los Héroes del 5 de Mayo, ${ }^{41}$ el altar simbólico agrega al presidente López Mateos como el nuevo héroe del presente, la ciudad de Puebla se engalana más en honor del mandatario que de la gesta de 1862, EL Sol de Puebla lo destaca en sus titulares: Puebla engalanada en honor de Ignacio Zaragoza y Adolfo López Mateos y para confirmarlo en el centro de la plana, la foto presidencial con la leyenda: ¡Bienvenido, Señor Presidente!. El diario reitera: Y será el señor Presidente y los altos funcionarios que formarán su comitiva quienes con su ejemplo patriótico serán una lección viva para el pueblo. ${ }^{42}$

43 A 100 años de la batalla y después de 94 conmemoraciones consecutivas, la imagen del invicto general se convierte en piedra y cede su lugar al señor presidente, quien ocupa el sitio central en la celebración. El programa largamente preparado se cumple puntualmente, desde la nueva carretera, la recepción es estruendosa y multitudinaria. En auto descubierto, el desfile triunfal por la avenida Reforma es encabezado por quien ha sabido llevar con tino los destinos de la Patria. Bajo una lluvia de serpentinas y confeti, la ceremonia ante el monumento al general Zaragoza es breve. ${ }^{43} \mathrm{El}$ desfile de 30,000 militares, las inauguraciones de la autopista México-Puebla, del Centro Cívico y del Auditorio de la Reforma son parte del espectáculo. Las enormes construcciones proyectadas dos años antes no se realizan, sin embargo, la ciudad cumple con creces su papel de anfitriona, Zaragoza aparece como una opaca estampa en esta historia. La celebración se transforma, se desplaza en el tiempo y el acto de propaganda del régimen de López Mateos desplaza al admirado Zaragoza.

44 Para el día siguiente no queda duda El Sol de Puebla confirma: Puebla vio en Adolfo López Mateos un símbolo de Zaragoza, y considera como la más cariñosa recepción que se haya dispensado a presidente alguno. ${ }^{44} \mathrm{El}$ mandatario es colocado así a la altura de los defensores de la Patria, encarna a Zaragoza, lo representa y como el prócer está igualmente presto a salvar a la República.

45 Para la celebración de los 150 años se anuncian festejos de nivel mundial, sin precedente, el objetivo es proyectar la ciudad y el estado de Puebla a través de obras monumentales y actividades de distinto tipo. Se mantienen antiguas prácticas, el desfile, diversos festivales y la reinauguración de viejos inmuebles no pueden faltar. El gobierno en turno persigue la espectacularidad, pero ahora irrumpen en ella nuevos 
protagonistas y nuevas murallas desplazan a aquella gente que recorría las calles y se apropiaba de la plaza y la tribuna. La ceremonia, en el escenario más vistoso que hayamos visto, es trasmitido por diversos canales televisivos. La conmemoración parecería tener lugar pero no memoria, el presente se impone en lo superfluo y se estaciona sin voltear hacia el pasado ante una gesta que parece desvanecerse, acelerada ante la presencia del espectáculo trasmitido por los medios de comunicación que impregnan con sus nuevas formas y tecnologías todo el acontecer. ${ }^{45}$

\section{BIBLIOGRAFÍA}

Aghulon, Maurice. Historia Vagabunda, Instituto Mora, México, 1994. 89.Catálogo de Bienes patrimoniales. Dirección de Bienes Patrimoniales. Puebla, 2010.

Echenique, D. Rafael Batalla del 5 de Mayo de 1862 en Puebla, Eusebio Sánchez Editor, México, 1884.

Glucksmann, André. El Discurso de la Guerra, Editorial Anagrama, Barcelona, 1969.

Gómez, Manuel Z. La vida del general Ignacio Zaragoza, Benemérita Universidad Autónoma de Puebla, Instituto de Ciencias Sociales y Humanidades, Consejo Cívico Cultural Cinco de Mayo, Biblioteca Poblana de Historia y Cultura 3, México, 2003.

La Batalla del 5 de Mayo de 1862, Ediciones Altiplano, México, 1970.

La Batalla del 5 de Mayo de 1862, Partes oficiales y telegramas, Ediciones Altiplano, Puebla, 1970.

Nora, Pierre, Les lieux de mémoire, LOM-Trilce, Chile, 2009.

Nora, Pierre, Présent, nation, mémoire, Éditions Gallimad, Francia, 2011.

Palou Pérez, Pedro Ángel, 5 de mayo de 1862, (edición bilingue) Editorial Las Animas, Puebla, 2011. 51.

Secretaría del H Ayuntamiento, Puebla de Zaragoza, 2008-2 Secretaría del H Ayuntamiento, Puebla de Zaragoza, 2008-2011. Catálogo de Bienes patrimoniales. Dirección de Bienes Patrimoniales. Puebla, 2010.

Zaragoza, Ignacio, Cartas y Documentos, Introducción y notas de Jorge L. Tamayo, Fondo de Cultura Económica, México, 2006.

\section{ANEXOS}

Anexo No. 1

Lista de Monumentos y otras expresiones con referencia a la batalla:

1.- Monumento a la Victoria; zona monumental de los Fuertes de Loreto y Guadalupe.

Año de instalación : 1962 
Creador: Eduardo Tamariz, y de los arquitectos Vicente Mendiola y Everardo Morales.

Este monumento fue inaugurado el 1962 junto con los demás existentes en la unidad cívica 5 de Mayo de los fuertes de Loreto y Guadalupe, en el primer centenario de la batalla de Puebla.

2.- Monumento a los defensores del 5 de Mayo; circuito interior Ejército de Oriente y final de la calzada de los fuertes.

Año de instalación : 1962.

3.- En 1962 la entonces Secretaría de Comunicaciones y Obras Públicas se dio a la tarea de construir un monumento para conmemorar el centenario de la victoria de Puebla contra los franceses por lo que el 5 de Mayo de ese año el entonces presidente Adolfo López Mateos inauguró esta estructura a la que el pueblo le llamó vulgarmente "El Taco".

4.- Monumento a Ignacio Zaragoza; glorieta de la calzada Ignacio Zaragoza frente a la unidad cívica 5 de Mayo.

La escultura ecuestre fue hecha en 1896.

Año de instalación en el sitio actual: 1976.

Inaugurada el 22 de noviembre de 1896 por el Presidente Porfirio Díaz; y estuvo ubicada hasta 1960 en el parque de las Piadosas (22 oriente y 10 norte) hasta fue trasladado a la unidad cívica 5 de Mayo con motivo de la celebración de dicha batalla. Obra del artista Jesús E Contreras.

Palacio Municipal. Placas.

1.- Marco en el pasillo. Planta baja I; año de colocación: 1962.

Fue colocada por el Ayuntamiento 1960-1963 para conmemorar el primer centenario de la batalla de Puebla.

2.- Marco en el pasillo Planta baja II; año de instalación: 1962.

Fue colocada por el ayuntamiento 1962-1963 para conmemorar el primer centenario de la batalla de Puebla.

3.- Marco II del Salón de Cabildos.

Sin referencias. Placa con la leyenda: "Gral de Div. Ignacio Zaragoza. Benemérito de la Patria en Grado Heroico". 5-V-1862.

Placas.

1.-Placa X

Fachada del templo de los Remedios.

10 oriente y privada 20 norte.

Año de instalación: 1962, 1996 y 1999.

No se cuentan con mayores referencias. Placa hecha en mármol con la leyenda: "En este fuerte de Los Remedios el Gral. Ignacio Zaragoza Seguín planeó la batalla del 5 de Mayo de 1862, escribió sus partes de guerra, telegramas y frases que se convirtieron en soberanía nacional, con memoria histórica" H Ayuntamiento de Puebla, 1999-2002. 
Nota: el catálogo no consigna la placa de la carta de Víctor Hugo a la ciudad de Puebla que está en el patio de la Casa de la Cultura. ${ }^{46}$

\section{NOTAS FINALES}

1. Telegrama de Ignacio de Zaragoza, dirigido al Presidente de la República, Puebla, Mayo 5 de 1862 , a las 7 horas y 3 minutos de la noche.

2. ECHENIQUE, 1884.

3. GLUCKSMAN, 1969: p. 34-35

4. NORA, 1992: p. 36.

5. Archivo del Ayuntamiento de Puebla, (AAP), Expedientes, T.239. leg. 83, ff. 256.

6. Dicha Junta organizó las solemnidades por cooperación entre sus miembros.

7. AAP, Expedientes, T. 241, leg 156, ff 63-65

8. Boletín Municipal, Tomo IV, No. 20, 10 de mayo de 1884 .

9. AAP., Expedientes Tomo 488, legajo 13, fojas 389.

10. Se conoció como cerro de Belén debido a que en la cima existió una capilla dedicada a Nuestra Señora de Belén. Fue hasta 1816 cuando se construyó otro templo dedicado a la Virgen de Guadalupe y de ahí tomó su actual nombre. La capilla de Guadalupe se destruyó en 1863 durante el sitio de la ciudad. De este fuerte solamente se conservan los muros de piedra y el foso y en el interior las ruinas de algunas habitaciones y del templo de Guadalupe. Lo anterior debido a que fue escenario de la batalla del 5 de mayo de 1862.

11. Boletín Municipal, Tomo I, No. 65, 5 de mayo de 1870. Publicación Oficial, Órgano del Gobierno del Estado Libre y Soberano de Puebla, Científica, e Instructiva y de Noticias y Avisos, Tomo I, No 65, 5 de mayo de 1870, p 1.

12. AAP, Expedientes. Volante anunciando el acontecimiento emitido por la Comisión de celebraciones, Puebla, 5 de mayo de 1899.

13. Negrete tuvo a lo largo de la historia independiente un destacado papel, durante la intervención francesa a pesar de ser conservador, se une al ejército republicano bajo las órdenes del general Ignacio Zaragoza, y participa en la Batalla del 5 de mayo de 1862, fue considerado uno de los héroes principales.

14. AAP. Expedientes, Tomo $823-1930$

15. Idem.

16. Idem.

17. AGHULON, 1994: p. 89.

18. AAP, 1888, Expedientes, Tomo 353, legajo 126 (22), ff 142-143vta, Comisión de Peticiones. Formado con la solicitud del Club Sufragio Popular para la erección de una estatua al General Ignacio Zaragoza en el Paseo de Hidalgo.

19. Ibid., Firma dicho documento Romualdo Zamacona, el 18 de mayo de 1888.

20. AAP., Serie Expedientes, Tomo 400, legajo 126, ff 195. Catálogo de bienes patrimoniales, Dirección de Bienes Patrimoniales, Puebla, 2010.

21. Ibid., Tomo 823 - 1930, 24 de Marzo de 1930. La actitud del mencionado ciudadanos es explicable por los numerosos robos que sufre la estatua. En mayo de 1930 nuevamente es robada la espada y el kepis que se le habían puesto, varios meses atrás unos pillos sustrajeron a espada y anteojos de la estatua del General Zaragoza en el Paseo de San Francisco, sin que jamás se lograra averiguar quien fue el ladrón que tuvo tan peregrina idea. Al llegar el 5 de Mayo la Jefatura de la Guarnición de la plaza, 
proporcionó en calidad de préstamo para el ayuntamiento, una espada flamante de general, para que el invicto general Zaragoza estuviese debidamente ataviado.

Los rateros vieron que ahora valía la pena de despojar nuevamente al héroe de su flamante espada y la mañana del miércoles siete del actual, apareció nuevamente la estatua como estaba antes de las fiestas. La Opinión, 11 de mayo de 1930. p1

22. El Sol de Puebla, 6 de junio de 1961 p. 1.- "Proyectan un monumento a la victoria del 5 de Mayo".

23. Idem.

24. Idem.

25. NORA, 2009: p. 32-33.

26. El Sol de Puebla, 7 de agosto de 1960, p.1.- "Instalará oficinas el comité de los festejos de 1962".

27. Ibid, 18 de junio de 1960, p.1.

28. Ibid, 22 de diciembre de 1961 p. 1.- "Iniciaron ayer la rehabilitación de los fuertes". El Sol de Puebla, 20 de enero de 1962

29. Ibid, 28 de enero de 1962

30. Ibid, 10 de febrero de 1962 (fotos) p. 1

31. Ibid, 11 de febrero de 1961, p. 1.

32. Idem., 11 de febrero de 1961.p. 1.-

33. Ibid., 18 de abril de 1962.

34. Ibid., 26 de mayo de 1960, p.1

35. Ibid., 26 de julio de 1961. p. 1.- "Trazan el programa de festejos para el centenario del 5 de Mayo".

36. Ibid., 11 de septiembre de 1961. p.1.- "Iluminarán los fuertes".

37. Ibid, 2 de octubre de 1961, p. 1.- "Urge reestructurar los museos de la ciudad".

38. Ibid., 9 de abril de 1961

39. Ibid., 12 de junio de 1961

40. Ibid., 17 de junio de 1961, p. 1.- "Que traigan los restos del Gral. Zaragoza".

41. Ibid., 4 y 5 de mayo de 1962, p. 1.

42. Idem.

43. La nota más breve de las actividades presidenciales fue la referente a este acto. El Sol de Puebla, 6 de mayo de 1962, p. 1.

44. El Sol de Puebla, 6 de mayo de 1962, p. 1.

45. NORA, 2011: p. 168-169.

46. SECRETARÍA DEL H AYUNTAMIENTO, Puebla de Zaragoza, 2008-2011. Catálogo de Bienes patrimoniales. Dirección de Bienes Patrimoniales. Puebla, 2010.

\section{RESÚMENES}

La conmemoración es un lugar de construcción y deconstrucción de símbolos, de acuerdo a las circunstancias adquiere un carácter específico, fluctúa, se reitera, recompone, deslava y dota de nuevos contenidos. Los próceres recorren un camino sinuoso, el cual se empieza a construir desde el momento mismo del acontecimiento, ahí nace el mito y se desarrolla el imaginario. Es la ciudad de Puebla la que ostenta con orgullo la soberanía, el 5 de Mayo se repite en la fiesta a 
través de palabras, fuegos, luces y sonidos. Los próceres muestran valores de dignidad y valentía, confirman así el triunfo efímero, que anuncia la derrota total del Imperio.

La commémoration est un moment de construction et déconstruction de symboles qui revêt un caractère particulier en fonction des circonstances, qui ondoie, se retire, remodèle, érode et s'enrichit de nouveaux contenus. Les grands hommes parcourent un chemin sinueux, dont la construction commence dès le moment où se produit l'événement: c'est là que naît le mythe et se déploie l'imaginaire. Tel est le cas de la ville de Puebla qui, dans un élan de fierté, affiche sa souveraineté: le 5 mai se répète dans la fête à travers les paroles, les feux, les lumières et les sonorités. Les grands hommes arborent les valeurs de la dignité et de la bravoure, confirmant ainsi le triomphe éphémère qui annonce la débâcle de l'Empire.

ÍNDICE

Mots-clés: Mexico, Empire de Maximiliano, fête, commémoration, 5 mai 1862

Palabras claves: México, Imperio de Maximiliano, fiesta, conmemoración, 5 de Mayo 1862

\section{AUTORES}

\section{ROSALINA ESTRADA URROZ}

Instituto de Ciencias Sociales y Humanidades, Alfonso Vélez Pliego, Benemérita Universidad Autónoma de Puebla

restrada47[at]yahoo.com

\section{ENRIQUE CANO GALINDO}

Doctorante Instituto de Ciencias Sociales y Humanidades, Alfonso Vélez Pliego, Benemérita Universidad Autónoma de Puebla 